lisadores de urânio são eficientes no tratamento de cargas muito diluídas de poluentes $(<1 \%)$, sem suplemento adicional de combustivel. A oxidação catalítica é um processo energeticamente menos intenso que a incineração, permitindo um melhor controlo dos produtos. Os únicos poluentes observados usando os óxidos de urânio são COx e $\mathrm{HCl}$ (este último, no caso dos compostos orgânicos clorados, facilmente removido à saída do reactor fazendo borbulhar o efluente gasoso em água). Não foram detectados outros produtos, nem mesmo ao nível de traços. Existem portanto vantagens económicas e ambientais importantes em relação a processos como a incineração, a qual mesmo nas melhores condiçōes pode originar sub produtos tóxicos, por exemplo dioxinas. Mesmo para a destruição de alcanos de cadeia curta (os alcanos pertencem à classe de VOCs mais difícil de destruir: aromáticos > alcanos halogenados > alcanos), foi também recentemente demonstrada a eficiência de catalisadores de óxido de urânio, os quais são activos a temperaturas relativamente baixas $\left(<600^{\circ} \mathrm{C}\right)$. A sua actividade catalítica sofre um aumento significativo se suportados em sílica.

Estes resultados mostram claramente que os catalisadores à base de urânio, e em particular os óxidos de urânio, podem ser a resposta para importantes problemas ambientais. Existindo processos bem estabelecidos para o manuseamento do urânio, dependentes basicamente de considerações de toxicidade química, e face a estes resultados, será a comercialização industrial deste tipo de catalisadores um objectivo utópico? Penso que não.

\section{Referências}

1. H. Collette, V. Deremince-Mathieu, Z Gabelica, J. B. Nagy, E. G. Derouane and J.
J. Verbist, J. Chem. Soc., Faraday Trans. 2, 83 (1987) 1263-1271.

2. Ref. 6 a 12 citadas em 1

3. S. D. Pollington, A. F. Lee, T. L. Overton, P. J. Sears, P. B. Wells, S. E. Hawley, I. D. Hudson, D. F. Lee and V. Ruddock, J. Chem. Soc, Chem. Commun., 8 (1999) 725-726.

4. G. H. Hutchings, C. S. Heneghan, I. D. Hudson and S. H. Taylor, Nature, 384

(1996) 341-343

5. S. H. Taylor and S. R. O'Leary, Appl. Catal. B, 25 (2000) 137-149.

tabela 1 Destruição de compostos orgânicos voláteis usando catalisadores de urânio [4].

\begin{tabular}{|c|c|c|c|c|c|}
\hline Catalisador & VOC $^{a}$ & $\ln (\mathrm{ppm})^{\circ}$ & $\mathrm{T}\left({ }^{\circ} \mathrm{C}\right)$ & $F\left(h^{-1}\right)^{c}$ & $h(\%)^{d}$ \\
\hline $\mathrm{U}_{3} \mathrm{O}_{8}$ & Clorobenzeno & 10000 & 350 & 70000 & 99,7 \\
\hline $\mathrm{U}_{3} \mathrm{O}_{8}$ & Clorobutano & 10000 & 350 & 70000 & 99,7 \\
\hline $\mathrm{CuCl} / \mathrm{KCl} / \mathrm{SiO}_{2}$ & Diclorometano & 10000 & 350 & 300 & 98,4 \\
\hline $\mathrm{U} / \mathrm{SiO}_{2}$ & Clorobenzeno & 10000 & 400 & 70000 & 99,9 \\
\hline $0,1 \% \mathrm{Pt} / \mathrm{Al}_{2} \mathrm{O}_{3}$ & Clorobenzeno & 398 & 530 & 30000 & 92,0 \\
\hline $\mathrm{U}_{3} \mathrm{O}_{8}$ & Benzeno & 10000 & 400 & 70000 & 99,9 \\
\hline $\mathrm{U} / \mathrm{SiO}_{2}$ & Benzeno & 10000 & 400 & 70000 & 99,9 \\
\hline $\mathrm{U} / \mathrm{SiO}_{2}$ & Tolueno & 10000 & 400 & 70000 & 99,9 \\
\hline
\end{tabular}

a) Composto orgânico volátil.

b) Carga à entrada do reactor.

c) $\mathrm{ml}$ de VOC convertidos por $\mathrm{ml}$ de catalisador e por hora.

d) Conversão.

\title{
O Urânio e a Electricidade
}

A DEMONSTRAÇÃO DA VIABILIDADE TÉCNICA da capacidade de estabelecer e manter, de forma controlada, uma cadeia de reacções de cisão de núcleos do urânio (reactor nuclear de Fermi e Zinn, 1942) constitui um dos mais sig- nificativos saltos da ciência e da tecnologia ocorridos no século XX. Antes dele, são de referir a proposta do princípio da equivalência entre a massa e a energia (Einstein, 1905); a sugestão da existência do núcleo atómico (Rutherford,
1911); as descobertas das reacçōes nucleares (Rutherford, 1919), do neutrão (Chadwick, 1932) e da cisão dos núcleos do urânio em resultado da interacção com neutrões (Hahn e Strassmann, 1938); a determinação do núme- 


\section{CENTRAIS NUCLEARES}

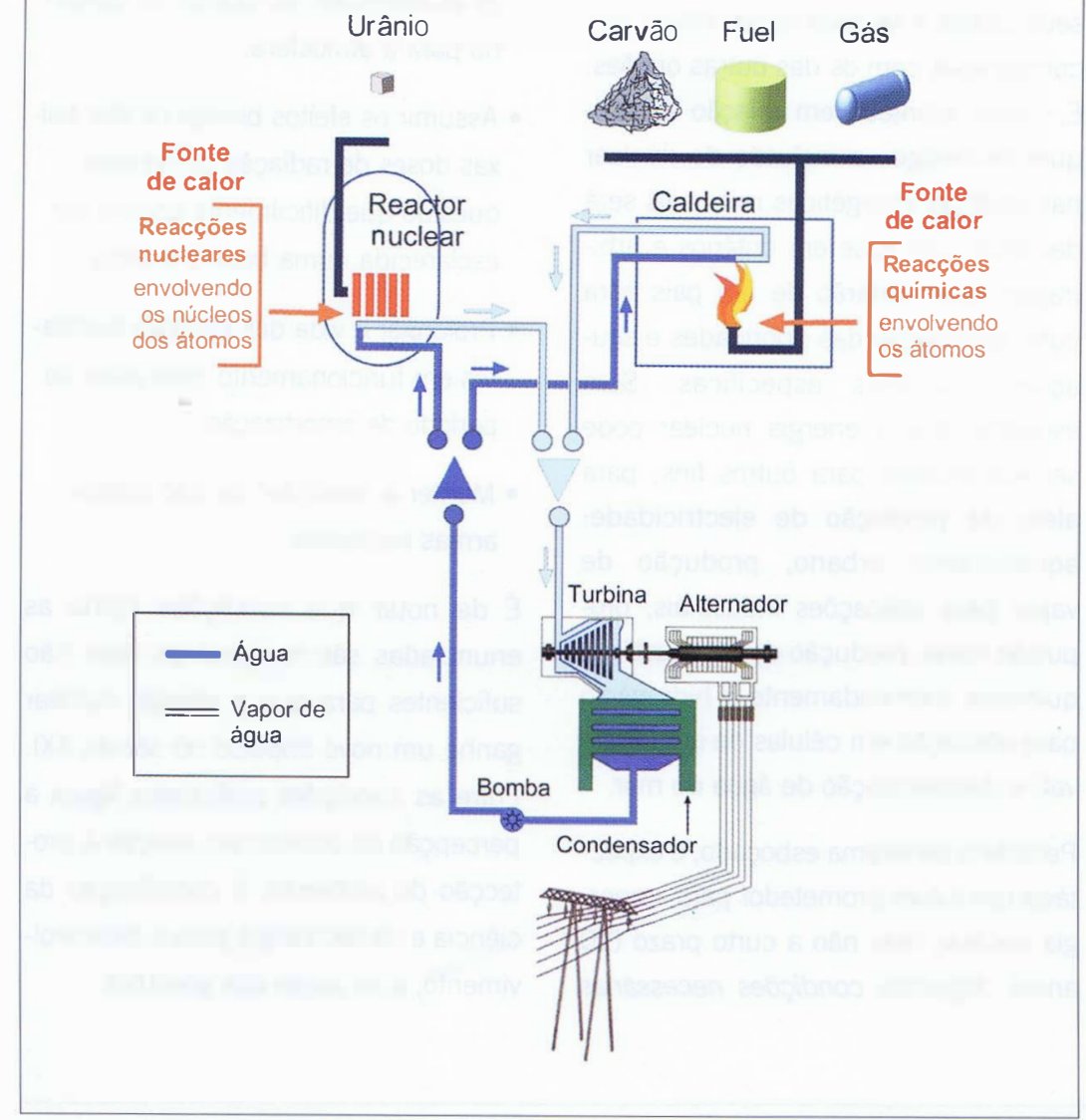

CENTRAIS CONVENCIONAIS figura 1 As centrais nucleares convencionais diferem essencialmente na fonte de calor ro de neutrões emitidos por cisão (Frédéric Joliot, Halban e Kowarski, 1939); e a transmutação do urânio-238 em plutónio-239 (Seaborg, Kennedy, Wahl e Segré, 1940).

O desenvolvimento da energia nuclear tem permitido alargar a base de recursos naturais (urânio) e artificiais (plutónio) utilizáveis para a produção de energia. No vasto conjunto de actividades englobadas na expressão "energia nuclear", avulta a concepção, construção e exploração de reactores e o fornecimento de serviços do ciclo do combustível. Este ciclo pode ser subdividido em três fases principais: (1) as operações que são realizadas a montante da utilização no reactor, desde a extracção e tratamento de minerais de urânio até à fabricação dos elementos de combustivel, passando pela purificação, conversạ̃o e (eventualmente) enriquecimento do urânio no isótopo U-235; (2) a utilização no reactor; (3) as operações realizadas a jusante da utilização, que compreendem a armazenagem do combustível usado e, no ciclo fechado, o reprocessamento deste combustível, o (eventual) reenriquecimento do urânio recuperado, a utilização do plutónio produzido para efeito da fabricação de elementos de combustível à base de óxidos mistos de urânio e plutónio e a armazenagem dos resíduos radioactivos.

Para fazer uma ideia do notável progresso verificado no aproveitamento do potencial energético do urânio - no sector onde tem tido maior impacte, que é a produção de electricidade -, é conveniente ter presente que a primeira ligação de um reactor nuclear a uma rede eléctrica (Obninsk, ex-URSS, $5 \mathrm{MWe}$ ) aconteceu doze anos após o funcionamento da "pilha" de Fermi. Em 1954, arrancou o primeiro dos quatro grupos electroprodutores (com uma potência unitária de $50 \mathrm{MWe}$ ) da central nuclear de Calder Hall, Reino Unido. Em 1 de
Janeiro de 2000, estavam em funcionamento 433 grupos electronucleares em 30 países (a que correspondia uma potência instalada de $349 \mathrm{GWe}$, sendo mais de $80 \%$ nos países da OCDE) e estavam em construçāo outros 37 grupos (31 GWe). Em 1999, as centrais nucleares produziram 2401 TWh (16\% da electricidade produzida no mundo, variando esta percentagem entre $4 \%$ e $75 \%$ nos países da OCDE, com um valor médio de 24\%)

Entre as forças que configurarão o futuro da Humanidade, ocupam posição destacada o crescimento demográfico (prevê-se que o número de habitantes da Terra aumente de cerca de 6.000 milhões em 2000 para cerca de 10.000 milhões em 2050), o desenvolvimento económico e social e a degradação do ambiente. Os serviços energéticos são essenciais para o desenvolvimento económico, prevendo-se que, em 2020, as necessidades de energia primária 
aumentem cerca de $10 \%$ nos países industrializados e dupliquem nos países em vias de desenvolvimento. Quanto à procura de electricidade, as previsões apontam para um aumento de $30 \%$ nos primeiros e para a triplicação dos consumos nos segundos. Isto implica a necessidade de duplicar, até 2020, a potência eléctrica instalada no mundo (que é, hoje, próxima de 3000 GWe), sem contar com a substituição de instalações obsoletas (com uma potência unitária de 600 GWe). Consequentemente, é recomendável:

- Manter todas as opções energéticas em aberto;

- Promover a competição entre as diversas opções energéticas.

Com efeito, o conceito de desenvolvimento sustentável corresponde mais ao itinerário de uma viagem do que a um destino. $\mathrm{O}$ objectivo imediato deve ser $\mathrm{o}$ de tomar as medidas convenientes para alargar o leque das opções disponíveis, em vez de suprimir nem que seja uma delas.
A energia nuclear é uma das opções energéticas cuja viabilidade está confirmada, em termos científicos, técnicos e económicos. As suas vantagens, os seus custos e os seus riscos devem ser comparados com os das outras opções. $E$, como acontece em relação a qualquer tecnologia, a inclusão do nuclear nas políticas energéticas nacionais será decidida com base em critérios e arbitragens que variarão de um país para outro em função das prioridades e situações nacionais específicas. Sem esquecer que a energia nuclear pode ser aproveitada para outros fins, para além da produção de electricidade: aquecimento urbano, produção de vapor para aplicações industriais, propulsão naval, produção de combustiveis químicos (nomeadamente o hidrogénio para utilização em células de combustivel) e dessalinização de água do mar.

Perante o panorama esboçado, é expectável um futuro prometedor para a energia nuclear, mas não a curto prazo (20 anos). Algumas condições necessárias para a emergência de uma "Segunda Era Nuclear" são as seguintes:

- Levar a sério a necessidade de reduzir as emissões de dióxido de carbono para a atmosfera;

- Assumir os efeitos biológicos das baixas doses de radiação como uma questão que dificilmente poderá ser esclarecida numa base científica;

- Prolongar a vida das centrais nucleares em funcionamento para além do período de amortização;

- Manter a "tradição" de não utilizar armas nucleares.

É de notar que condições como as enunciadas são necessárias mas não suficientes para que a energia nuclear ganhe um novo impulso no século XXI. Entre as condições suficientes figura a percepção do público em relação à protecção do ambiente, à contribuição da ciência e da tecnologia para o desenvolvimento, e ao papel dos governos.

figura 2 Ciclo do combustivel nuclear.

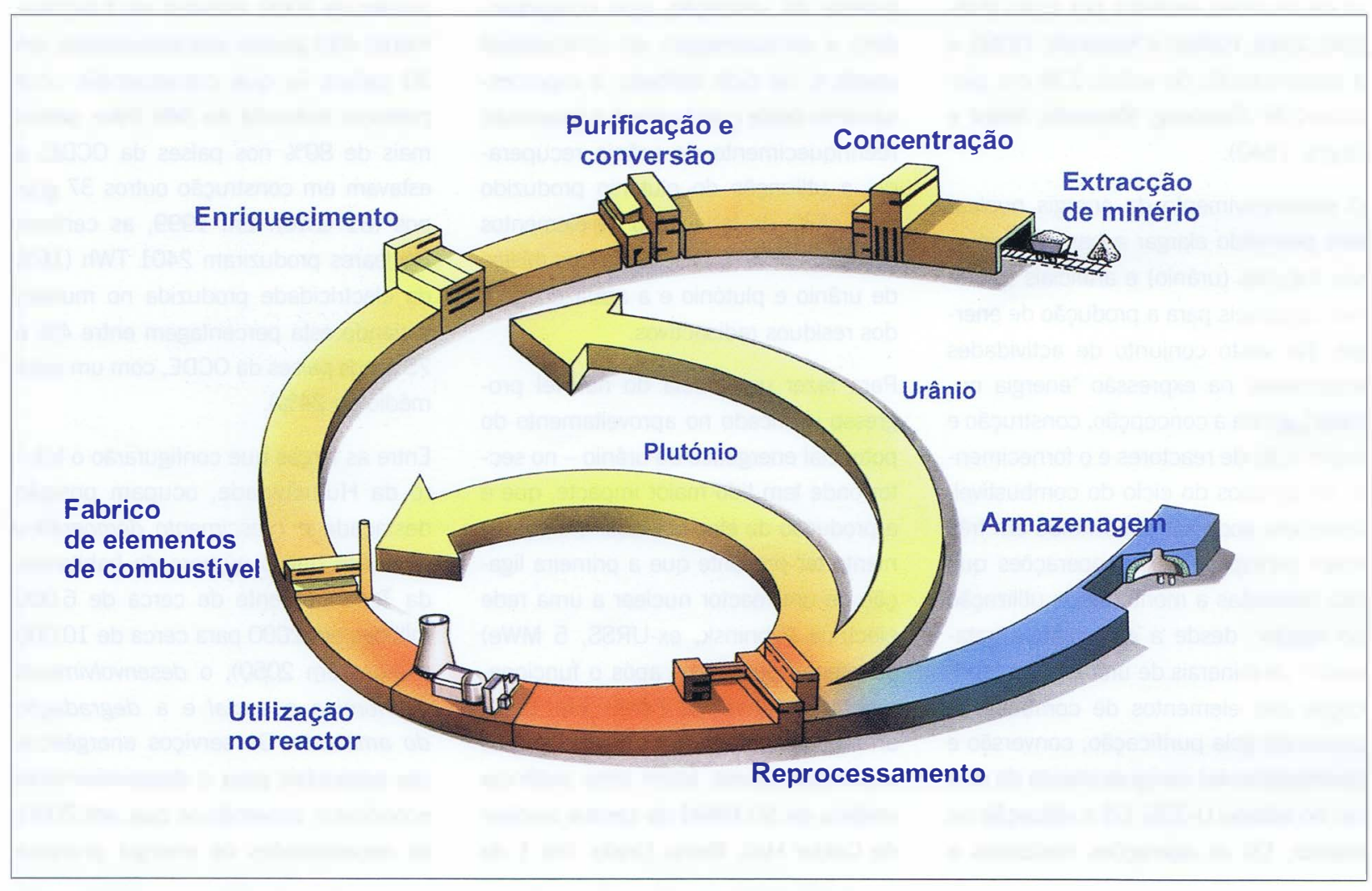




\section{Técnicar Lebortosicis de Quimica Vides Cassette}

Com 7 blocos curtos e independentes, este trabalho foi concebido para apoiar as aulas de Técnicas Laboratoriais de Química destinadas a alunos do Ensino Secundário e das cadeiras introdutórias de Química do Ensino Superior. Os procedimentos apresentados são clássicos, simples e adequados para estes níveis de ensino, onde a transparência dos princípios químicos a ilustrar e a necessidade de adopção de boas práticas laboratoriais são da maior importância formativa.

\section{Índice}

Pesagem e Preparaçào de Soluçðes (11 minutos)

Operação de balanças técnicas e de precisão

Preparação de soluções rigorosas enão rigorosas

Análise Volumétrica Quantitativa (11 minutos)

Operação com pipetas e buretas

Titulações manuais

Recristalização e Filtração (24 minutos)

Recristalização por dissolução e arrefecimento

Filtração em papel e à trompa

Filtração a quente

ExtracçãoLiquido-Líquido (7 minutos)

Operação com ampolas de decantação

Destilação (23 minutos)

Destilações simples, fraccionada,

a pressão reduzida e por arrastamento de vapor

TLC e Pontos de Fusão (9 minutos)

Cromatografia de Camada Fina

Enchimento de capilares para p.f.

Sopragem de Vidro (11 minutos)

Estirar tubos capilares

Cortar e dobrar tubos de vidro

Demonstração do fabrico e reparação de material de vidro executada por sopradores de vidro profissionais do IST.

\author{
Ficha Técnica \\ Coordenação \\ Carlos Romão \\ Hermínio Diogo \\ Texto e Locução \\ Carlos Romão \\ Execuçao Laboratorial \\ Hermínio Diogo \\ João Paulo Telo \\ Conceição Mesquita \\ João Ferreira \\ Carlos Nuno \\ José Luis Rodrigues \\ Filmagem e Montagem Video \\ Luís Raposo \\ Anabela Martins \\ Hermínio Costa \\ Joaquim Pinto \\ Produção \\ Núcleo de Audio Visuais \\ do IST \\ Apresentação e Duração \\ 1h 36min; Cassette VHS \\ Distribuição Exclusiva \\ Sociedade Portuguesa de Química
}

Encomendas à SPQ, Av. da República 37, 4º 1050 Lisboa

Tel: 217934637 / Fax: 217952349

Preço: Instituições e não sócios $7500 \$ 00+$ IVA + portes

Sócios $6000 \$ 00+$ IVA + portes 